\title{
The effect of vapocoolant spray on pain due to intravenous cannulation in children: a randomized controlled trial
}

\author{
Ken J. Farion MD, Karen L. Splinter MD, Kym Newhook BScN RN, Isabelle Gaboury MSc, \\ William M. Splinter MD
}

$\infty$ See related research paper by Taddio and colleagues, page 37, and related commentary by Anand, page 11

\section{ABSTRACT}

Background: Established noninvasive pharmacologic means of alleviating pain and anxiety in children undergoing intravenous cannulation are time-consuming, and thus impractical for routine use in the emergency department. Vapocoolant sprays provide transient skin anesthesia within seconds of application. We compared the effect of a new vapocoolant spray to placebo on pain due to intravenous cannulation in children.

Methods: In this double-blind randomized controlled trial, which we conducted between June 1 and Sept. 12, 2006, 80 children aged 6-12 years received either vapocoolant spray or placebo before cannulation. Children rated their pain using a $100-\mathrm{mm}$ colour visual analogue scale. Secondary outcomes included success rate on first attempt at cannulation and pain ratings by the children's parents, nurses and child life specialists.

Results: We found a modest but significant reduction in pain with the use of vapocoolant spray (mean difference $19 \mathrm{~mm}$, $95 \%$ confidence interval $[\mathrm{Cl}] 6-32 \mathrm{~mm} ; p<0.01)$. Cannulation on first attempt was more often successful with the use of vapocoolant spray $(85.0 \%)$ than with placebo $(62.5 \%)$ (mean difference $22.5 \%, 95 \% \mathrm{Cl} 3.2 \%-39.9 \% ; p=0.03$ ). The number needed to treat to prevent 1 cannulation failure was $5(95 \% \mathrm{Cl} 3-32)$. Parents $(p=0.04)$, nurses $(p=0.01)$ and child life specialists $(p<0.01)$ considered the children's pain to be reduced with the use of vapocoolant spray.

Interpretation: The vapocoolant spray in our study quickly and effectively reduced pain due to intravenous cannulation in children and improved the success rate of cannulation. It is an important option to reduce childhood procedural pain in emergency situations, especially when time precludes traditional interventions.

(ClinicalTrials.gov trial register no. NCT00130650.)

Une version française de ce résumé est disponible à l'adresse www.cmaj.ca/cgi/content/full/179/1/31/DC1

CMAJ 2008;179(1):31-6

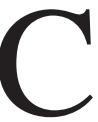
hildren frequently undergo intravenous cannulation in the emergency department. This painful procedure causes considerable stress and anxiety for children and their parents. ${ }^{1}$ Failure to alleviate pain results in an uncooperative child, unsuccessful procedures (increased reattempts), prolonged procedure time and dissatisfaction with care for all involved. ${ }^{2}$ Although pain may be reduced by behavioural and pharmacologic interventions (e.g., ageappropriate patient preparation, parental presence, distraction techniques, subcutaneous local anesthetics, topical anesthetic and systemic anesthetics), most of these preparations are impractical in nonelective settings because they are too timeconsuming. ${ }^{3-12}$ Novel delivery approaches and new medication compositions may decrease this time. ${ }^{13,14}$

Vapocoolant sprays are rapid-acting alternatives to topical anesthetics. They provide transient anesthesia via evaporation-induced skin cooling, which reduces pain. Results from studies of earlier vapocoolant sprays indicated that they reduced pain due to vaccine injection in children and adults, ${ }^{15-18}$ but not pain due to intravenous cannulation in children. ${ }^{19,20} \mathrm{We}$ sought to determine whether a new product, Pain Ease (Gebauer Company, Cleveland, Ohio), would reduce pain with intravenous cannulation in children.

\section{Methods}

\section{Study design and population}

We conducted a double-blind randomized controlled trial between June 1 and Sept. 12, 2006, at the Children's Hospital of Eastern Ontario, an academic, tertiary care children's hospital in Ottawa, Ontario. At the time of the study, common practice related to intravenous cannulation in our Emergency Department included standardized patient preparation, distraction by a child life specialist when available and use of topical anesthetic cream when time permitted.

Children aged 6-12 years were eligible for enrolment if they required urgent intravenous cannulation. We considered the procedure to be urgent if it was required by the treating physician within 30-45 minutes, which did not allow enough time for the use of topical anesthetic cream (recommended application time is 45-60 minutes before the procedure $\left.{ }^{9}\right)$. We excluded patients if there was a need for emergency vascular access, if there were contraindications to the use of vapocoolant spray (e.g., sensitivity to

From the Departments of Pediatrics (Farion), Emergency Medicine (Farion) and Anesthesiology (K.L. Splinter, W.M. Splinter), University of Ottawa; the Emergency Department (Newhook), Children's Hospital of Eastern Ontario; and the Children's Hospital of Eastern Ontario Research Institute (Gaboury), Ottawa, Ont. 
halogenated hydrocarbons, peripheral vascular disease), if we were unable to complete the pain assessment or if the patient had already received a topical anesthetic cream. We approached patients only when a child life specialist was available (about 8 hours per day). We obtained written informed consent from parents and patients.

The Children's Hospital of Eastern Ontario Research Ethics Board approved the study. To ensure that study interventions did not lead to adverse outcomes or unacceptably high cannulation failure rates, a data safety monitoring committee reviewed the complication outcomes of 40 patients. The results of the interim analysis were inconclusive, so the study completed recruitment.

\section{Procedures}

We randomly assigned patients to the active treatment or placebo group in blocks of 10 using a random number generator. Research personnel (who were not involved in patient enrolment) masked similar canisters of active treatment or placebo, labelled them with a unique identifier and placed them in sequentially numbered opaque, sealed envelopes. Once eligibility and consent were confirmed, the research assistant obtained the next envelope in sequence and recorded

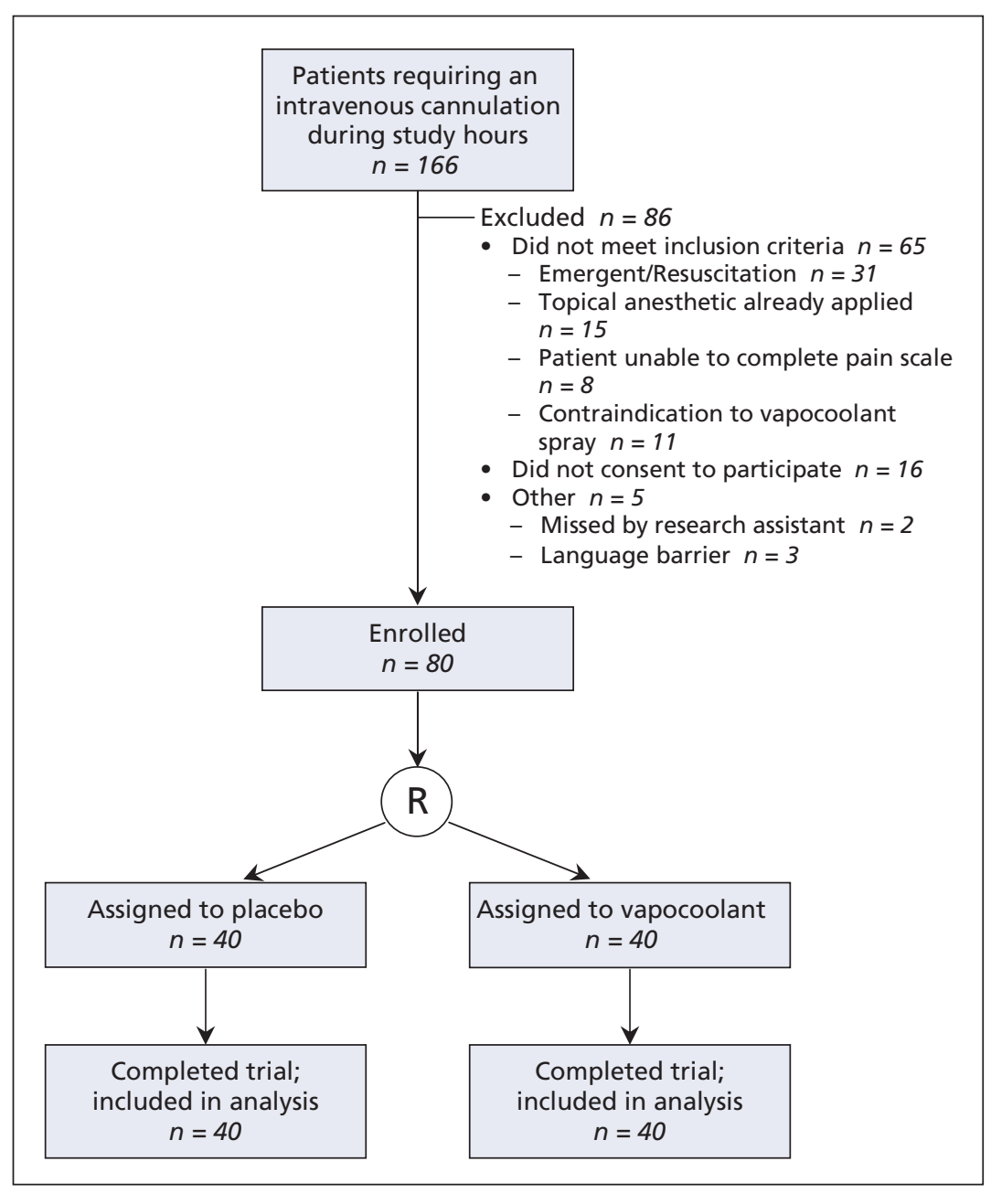

Figure 1: Flow of patients through the trial. $R$ = randomization. the envelope number and canister identifier on the enrolment $\log$ and data collection forms. On completion of the study, we compared the enrolment log and master randomization list to identify any allocation violations.

At baseline, we recorded the patient's age, sex and history of intravenous cannulation. Anxiety can influence pain perception, so we asked patients to rate their anxiety about the cannulation by drawing a line on a $100-\mathrm{mm}$ colour visual analogue scale, ${ }^{22}$ on which 0 indicated "not scared" and 100 indicated "extremely scared." Two researchers blinded to treatment allocation independently measured the distance in millimetres between 0 and the patient's line. We recorded the patient's baseline anxiety level as the mean of these 2 measurements. The other details that we recorded at baseline included the location of the cannulation attempt, the cannula size (22 or 24 gauge), nurse experience, the child life specialist present and the distraction activity (e.g., I-Spy book, blowing bubbles, counting, television) chosen by the child.

All patients received standardized age-appropriate preparation and distraction from 1 of 2 trained child life specialists during the cannulation attempts. The nurse selected and prepared the dorsum of the hand or antecubital fossa. Next, the research assistant sprayed the cannulation site while all others in the room looked away. We timed the duration of the spray with a stopwatch. Residue was removed with a sterile gauze. Within the next 60 seconds, the nurse turned back and attempted the cannulation. If the attempt was unsuccessful, we completed all data collection before subsequent attempts. We did not measure the outcomes of subsequent attempts.

Patients who were randomly assigned to the active treatment group received vapocoolant spray containing 1,1,1,3,3-pentafluoropropane and 1,1,1,2-tetrafluoroethane (Pain Ease, Gebauer Company, Cleveland, Ohio) at room temperature, sprayed from a distance of 8 $18 \mathrm{~cm}$ for 4-10 seconds until the skin blanched. Patients who were assigned to the placebo group received sterile, normal saline spray (Nature's Tears, Bio-logic Aqua Technologies, Grants Pass, Oregon) at room temperature, in a similar fashion.

\section{Outcome measures}

The primary outcome measure was the children's self-reported pain during intravenous cannulation. Patients rated their pain immediately following the cannulation attempt by drawing a line on a $100-\mathrm{mm}$ colour visual analogue scale, ${ }^{22}$ on which 0 indicated "no pain" and 100 indicated "unbearable pain." Two researchers blinded to treatment allocation independently measured the distance in millimetres between 0 and the patient's line. We recorded the patient's pain during cannulation as the mean of these 2 measurements. 
Secondary outcome measures included the success rate on first attempt and assessments from the children's parents, nurses and child life specialists. These observers independently rated how much pain the child experienced using 4point categorical scale varying from "no pain" to "large pain." They rated how satisfied they were with the child's pain management using a 5-point Likert scale varying from "very unsatisfied" to "very satisfied." In addition, each observer speculated which spray they thought the child had re- ceived. Finally, the nurses rated the ease of the cannulation using a 5-point Likert scale varying from "very difficult" to "very easy" and rated the impact the spray had on the attempt using a 5-point Likert scale varying from "significantly more difficult" to "significantly easier."

\section{Statistical analysis}

To detect a clinically important reduction of $15 \mathrm{~mm}$ on the visual analogue pain scale, ${ }^{23}$ we chose a sample size of

Table 1: Demographic and baseline characteristics of 80 children requiring intravenous cannulation, by study group

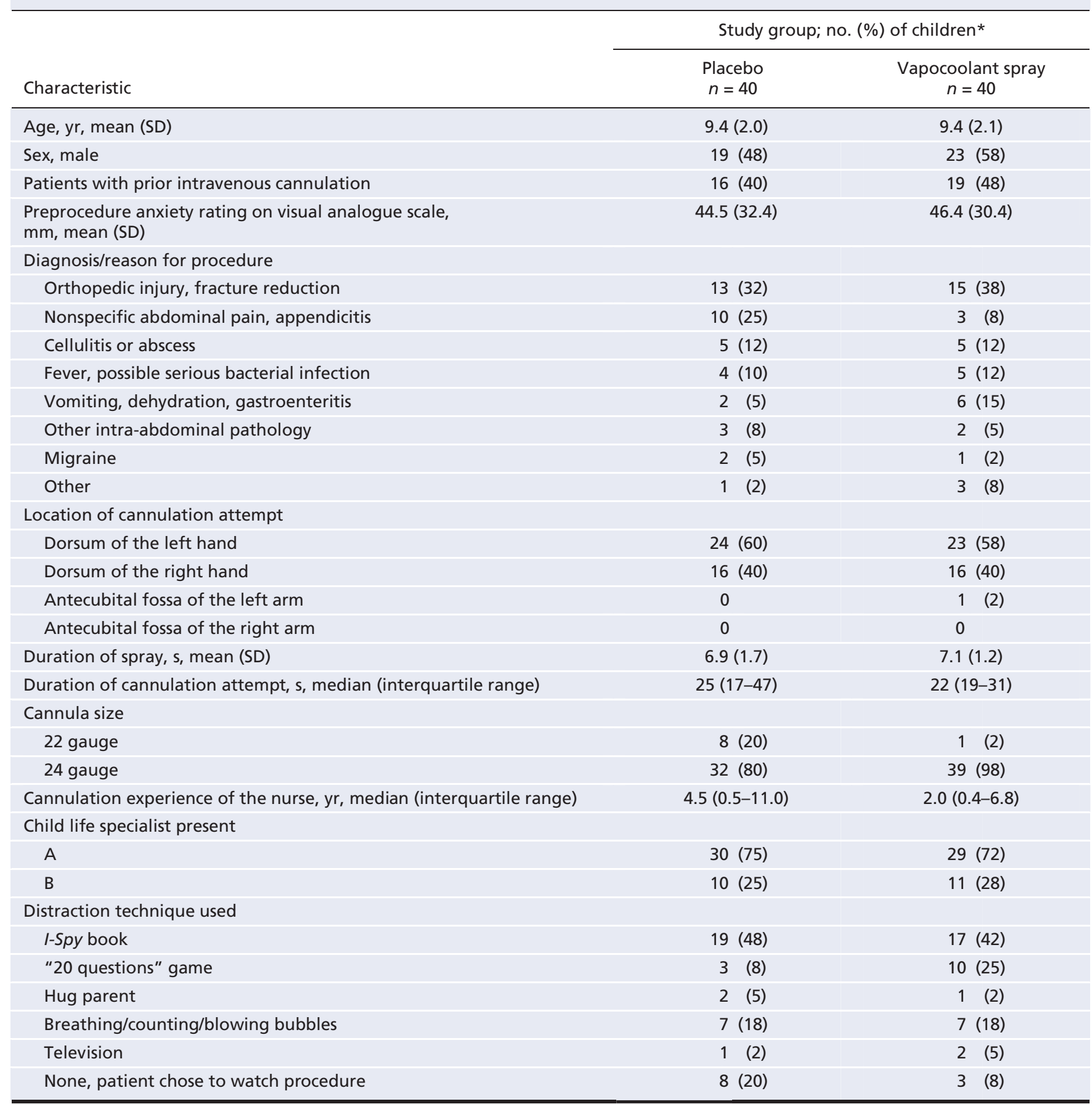

Note: $\mathrm{s}=$ seconds, $\mathrm{SD}=$ standard deviation.

*Unless indicated otherwise. 
68 children (34 per treatment group). We assumed a 2-tailed test, power of $80 \%$, and type I error rate of 0.05 . We increased the sample to 80 (40 per group) to compensate for dropouts or deviations in protocol.

We generated descriptive statistics to summarize participants' profiles according to treatment group. We compared mean pain scores using a $t$ test. We fit a linear regression model to determine the association between the study group and pain score, adjusting for the size of cannula used. We categorized pain scores as "no pain" (0-9 $\mathrm{mm})$, "minimal pain" (10-39 mm), "moderate pain" (40-69 $\mathrm{mm})$ or "severe pain" (70-100 $\mathrm{mm})$, and compared the data using the

\begin{tabular}{|c|c|c|c|}
\hline $\begin{array}{l}\text { Pain rating/ } \\
\text { category }\end{array}$ & $\begin{array}{c}\text { Placebo } \\
n=40\end{array}$ & $\begin{array}{l}\text { Vapocoolant spray } \\
\qquad n=40\end{array}$ & $p$ value \\
\hline $\begin{array}{l}\text { Rating on } \\
\text { visual } \\
\text { analogue } \\
\text { scale, mm, } \\
\text { mean (SD) }\end{array}$ & 56.1 (31.9) & $36.9 \quad(27.5)$ & $<0.01$ \\
\hline Category, no. (\%) & & & 0.01 \\
\hline $\begin{array}{l}\text { No pain } \\
(0-9 \mathrm{~mm})\end{array}$ & $2(5)$ & $6 \quad(15)$ & \\
\hline $\begin{array}{l}\text { Minimal } \\
\text { pain (10- } \\
39 \mathrm{~mm})\end{array}$ & $11(28)$ & 14 (35) & \\
\hline $\begin{array}{l}\text { Moderate } \\
\text { pain }(40- \\
69 \mathrm{~mm})\end{array}$ & $11(28)$ & $15 \quad(38)$ & \\
\hline $\begin{array}{l}\text { Severe pain } \\
(70-100 \mathrm{~mm})\end{array}$ & $16(40)$ & $5 \quad(12)$ & \\
\hline
\end{tabular}

Note: SD = standard deviation.
Wilcoxon rank-sum test. We assessed the difference in rates of success between the 2 study groups using a logistic regression model to allow further adjustment for cannula size. We compared the distribution of ordinal responses from the parents, nurses and child life specialists using Wilcoxon ranksum tests. We determined the success of blinding using the Fisher exact test.

\section{Funding and commercial interests}

Gebauer Company provided the Pain Ease vapocoolant spray and the placebo spray used in the study. The company provided no other support, nor did it influence the design, conduct or reporting of the trial.

\section{Results}

During hours when all of the required study personnel were available, 166 children required intravenous cannulation. Figure 1 describes our selection process. We excluded 86 patients because they did not meet our inclusion criteria, did not consent to participate or because of other reasons. We enrolled 80 children, randomly assigned them to the active treatment or placebo group and completed the study protocol without deviation. Baseline characteristics (Table 1) did not differ between the 2 groups, with the exception of cannula sizes; more patients in the active treatment group than patients in the control group received 24-gauge cannulae. We adjusted further analyses for this imbalance.

We found that pain was significantly reduced with the use of the vapocoolant spray (mean score $37 \mathrm{~mm}$ v. $56 \mathrm{~mm}$ with placebo), for a mean difference of $19 \mathrm{~mm}$ (95\% confidence interval [CI] 6-32 mm; $p<0.01$ ) (Table 2). This difference remained significant $(p<0.01)$ after we adjusted for needle size. Half of the children (20/40) who received the vapocoolant spray reported having "no pain" or "minimal pain,"

Table 3: Rating by parents, child life specialists and nurses of childrens pain an d pain management

\begin{tabular}{|c|c|c|c|c|c|c|c|c|c|}
\hline Rating & \multicolumn{3}{|c|}{ Parents' ratings } & \multicolumn{3}{|c|}{ Child life specialists' ratings } & \multicolumn{3}{|c|}{ Nurses' ratings } \\
\hline Level of pain & & & 0.04 & & & 0.03 & & & 0.01 \\
\hline No pain & $6(15)$ & $11(28)$ & & $1(2)$ & $4(10)$ & & $7(18)$ & $13(32)$ & \\
\hline Small pain & $15(38)$ & $17(42)$ & & $23(58)$ & $31(78)$ & & $17(42)$ & $21(52)$ & \\
\hline Large pain & $5(12)$ & 0 & & $1(2)$ & 0 & & $3(8)$ & 0 & \\
\hline $\begin{array}{l}\text { Satisfaction with pain } \\
\text { management }\end{array}$ & & & 0.07 & & & $<0.01$ & & & 0.33 \\
\hline Very unsatisfied & $2(5)$ & $1(2)$ & & 0 & 0 & & $1(2)$ & $1(2)$ & \\
\hline Unsatisfied & $3(8)$ & 0 & & $13(32)$ & $5(12)$ & & $6(15)$ & $2(5)$ & \\
\hline
\end{tabular}

*Values represent no. (\%) of children for whom rating applied. 


\begin{tabular}{|c|c|c|c|}
\hline Rating & $\begin{array}{l}\text { Placebo* } \\
n=40\end{array}$ & $\begin{array}{l}\text { Vapocoolant* } \\
n=40\end{array}$ & $p$ value \\
\hline $\begin{array}{l}\text { Technical difficulty } \\
\text { of cannulation } \\
\text { attempt }\end{array}$ & & & 0.02 \\
\hline Very difficult & $2(5)$ & 0 & \\
\hline Difficult & $10(25)$ & $5(12)$ & \\
\hline Neutral & $10(25)$ & $6(15)$ & \\
\hline Easy & $9(22)$ & $14(35)$ & \\
\hline Very easy & $9(22)$ & $15(38)$ & \\
\hline $\begin{array}{l}\text { Influence of spray on } \\
\text { cannulation attempt }\end{array}$ & & & 0.01 \\
\hline $\begin{array}{l}\text { Significantly more } \\
\text { difficult }\end{array}$ & $3(8)$ & $2(5)$ & \\
\hline $\begin{array}{l}\text { Somewhat more } \\
\text { difficult }\end{array}$ & $31(78)$ & $22(55)$ & \\
\hline Neutral & $5(12)$ & $9(22)$ & \\
\hline Somewhat easier & $1(2)$ & $7(18)$ & \\
\hline Significantly easier & 0 & 0 & \\
\hline
\end{tabular}

*Values represent no. (\%) of children for whom rating applied.

compared with $32 \%$ (13/40) of the children who received placebo $(p=0.01)$.

Successful cannulation on the first attempt occurred significantly more often after the use of the vapocoolant spray $(34 / 40[85 \%])$ than after the placebo spray $(25 / 40[62.5 \%])$, for a mean difference of $22.5 \%$ (95\% CI 3.2\%-39.9\%; $p=$ $0.03)$. This difference remained significant $(p=0.02)$ after we adjusted for needle size.

Secondary outcome ratings by the parents, child life specialists and nurses are presented in Table 3. Pain ratings by all 3 groups of observers favoured the vapocoolant spray. Child life specialists' ratings of satisfaction with pain management significantly favoured the vapocoolant spray while parents and nurses were satisfied similarly with pain management in both groups. Nurses rated the technical ease of the attempt as "easy" or "very easy" more often when the vapocoolant spray was used than when placebo was used (mean difference $27.5 \%, 95 \%$ CI $5.9 \%-45.8 \% ; p=0.02$ ) (Table 4). They rated the attempt as "somewhat easier" or "significantly easier" more often with the vapocoolant spray than with placebo (mean difference $25 \%, 95 \%$ CI $5.4 \%-42.3 \% ; p=0.01)$.

Parents correctly identified which spray was given to 47 (59\%) of 79 patients $(p=0.12)$. Nurses correctly identified the spray for $52(65 \%)$ of 80 patients $(p=0.01)$, and the child life specialists were correct for $65(81 \%)$ of 80 patients $(p<0.01)$.

We identified no immediate or delayed adverse outcomes.

\section{Interpretation}

We found that, compared with placebo, the vapocoolant spray resulted in a $34 \%$ absolute reduction in children's pain due to intravenous cannulation. About 18\% more children who received the vapocoolant spray than children who received placebo reported having "no pain" or "minimal pain." This reduction in pain was achieved without delay to cannulation. Also, we found that the success of cannulation increased when vapocoolant spray was used; the number needed to treat to prevent 1 cannulation failure was 5 (95\% CI 3-32).

Prior studies of vapocoolant sprays did not show a reduction in pain due to intravenous cannulation in children. ${ }^{19,20} \mathrm{We}$ do not know whether changes in the product composition (refrigerant), application process, speed of evaporation or trial methodologies were responsible for our positive results.

In the prior studies, ${ }^{19,20}$ the application time of the spray was limited to 5 seconds. As recommended by the manufacturer of the spray we used, ${ }^{21}$ we allowed up to 10 seconds to achieve skin blanching. Our cannulation attempt occurred within 60 seconds after application because vapocoolant sprays have a brief duration of action (30-60 seconds). In the other studies ${ }^{19,20}$ the reported timing of cannulation was vague. The child life specialists in our study used standardized preparation and distraction techniques to reduce children's anxiety. ${ }^{24,25}$ We measured pain with a visual analogue scale, which is a reliable, valid and commonly used method of assessment for school-aged children. ${ }^{23}$ The minimum clinically important differences in pain scores that have been previously reported varied from 10 to $24 \mathrm{~mm} .^{26,27}$ Our choice of a reduction of $15 \mathrm{~mm}$ on the pain scale ${ }^{23}$ represents a moderate but important effect. There is no ideal control spray for studies such as ours. In earlier trials, ${ }^{19,20}$ isopropyl alcohol was used for the control spray, which may have had an anesthetic effect because of its rate of evaporation. The pain scores that we observed in patients who received placebo were similar to those reported in studies that used other placebos ${ }^{28}$ but they were markedly higher than results for a placebo group in a study involving adults. ${ }^{29}$ Such a difference is to be expected because children typically have higher baseline pain levels, possibly because of anticipatory distress.

The reduction in pain that we observed is similar to that reported in studies of other topical interventions. ${ }^{9,11,13,30} \mathrm{We}$ did not anticipate the improved cannulation success rate in the vapocoolant group because we expected that vasoconstriction might make cannulation more difficult. Success rates with other agents have been varied and do not support our observation. . $2,20,30^{2}$

Our study has some limitations. We did not measure the discomfort associated with the intervention. For example, some patients experienced a burning sensation as their skin was rapidly cooled. Timing prevented us from assessing this discomfort separately from the pain due to intravenous cannulation. Another concern was blinding. We successfully blinded parents to the group allocation, but despite our efforts, we were unable to blind the nurses or child life specialists. We anticipated that the 2 child life specialists would recognize a difference in the patients' behaviour through repeated participation in the study. However, because 40 different nurses participated, we did not anticipate that they would recognize a difference. Residual skin blanching from 
the active treatment is likely responsible. Finally, we did not assess whether we successfully blinded the children; however, similar to parents, child life specialists and nurses, we should have asked the children whether they thought they had received the active treatment or placebo.

Our results have clinical implications. The vapocoolant spray that we used provided quick and effective reduction of pain due to intravenous cannulation without delaying the procedure. This feature is especially important when time is limited, such as in a busy office practice or emergency department, where topical methods of pain relief have not traditionally been available. As well, effective pain relief combined with improved success on first cannulation attempt results in fewer repeat attempts, decreased procedure times and improved satisfaction among children, parents and health care providers. This decreases conditioned anxiety responses, heightened pain perception associated with future procedures $^{31-33}$ and risk of "blood-injection-injury phobia." ${ }^{34}$

The vapocoolant spray that we studied is a nonflammable, nontoxic and ozone-friendly spray. It is easy to apply, is less expensive than alternatives, works instantaneously, does not require a needle or needle-like device and is relatively innocuous. It can be used in a variety of procedures, such as intravenous cannulation, venipuncture and vaccine injection. Side effects include rare allergic reactions and minor temporary skin changes. Unfortunately, skin changes may become permanent if the topical spray exceeds 10 seconds because severe local hypothermia may cause the death of local cells.

\section{This article has been peer reviewed.}

Competing interests: None declared.

Contributors: Ken Farion, Karen Splinter, Kym Newhook and William Splinter were responsible for the conception and design of the study. Ken Farion, Kym Newhook and William Splinter were responsible for data acquisition. Ken Farion, Isabelle Gaboury and William Splinter analyzed and interpreted the data. Isabelle Gaboury was responsible for statistical analysis. Ken Farion drafted the article. Karen Splinter, Kym Newhook, Isabelle Gaboury and William Splinter critically revised the manuscript for important intellectual content. All of the authors approved the final version for publication.

Acknowledgements: We thank the research assistants Josdalyne Anderson and Susan Tan, the child life specialists Christina VanderPloeg and Lisa O'Kane, and the nurses of the Emergency Department at the Children's Hospital of Eastern Ontario for their help with this research.

The Pain Ease vapocoolant spray and placebo spray were provided by Gebauer Company. No other support was received, nor did the company influence the design, conduct or reporting of this trial.

\section{REFERENCES}

1. Kennedy RM, Luhmann JD. Pharmacological management of pain and anxiety during emergency procedures in children. Paediatr Drugs 2001;3:337-54.

2. McGrath PJ, McAlpine L. Psychologic perspectives on pediatric pain. J Pediatr 1993;122(5 Pt 2):S2-8.

3. Zempsky WT, Cravero JP, Knapp JF, et al. Relief of pain and anxiety in pediatric patients in emergency medical systems. Pediatrics 2004;114:1348-56.

4. MacLaren JE, Cohen LL. A comparison of distraction strategies for venipuncture distress in children. J Pediatr Psychol 2005;30:387-96.

5. Duff AJA. Incorporating psychological approaches into routine paediatric venepuncture. Arch Dis Child 2003;88:931-7.
6. Sparks L. Taking the "ouch" out of injections for children: using distraction to decrease pain. MCN Am J Matern Child Nurs 2001;26:72-8.

7. Megel ME, Houser CW, Gleaves LS. Children's responses to immunizations: lullabies as a distraction. Issues Compr Pediatr Nurs 1998;21:129-45.

8. Jimenez N, Bradford H, Seidel KD, et al. A comparison of a needle-free injection system for local anesthesia versus EMLA for intravenous catheter insertion in the pediatric patient. Anesth Analg 2006;102:411-4.

9. Lander JA, Weltman BJ, So SS. EMLA and amethocaine for reduction of children's pain associated with needle insertion [review]. Cochrane Database Syst Rev 2006;(3):CD004236.

10. Chen BK, Cunningham BB. Topical anesthetics in children: agents and techniques that equally comfort patients, parents and clinicians. Curr Opin Pediatr 2001;13: 324-30.

11. Houck CS, Sethna NF. Transdermal analgesia with local anesthetics in children: review, update and future directions. Expert Rev Neurother 2005;5:625-34.

12. Taddio A, Soin HK, Schuh S, et al. Liposomal lidocaine to improve procedural success rates and reduce procedural pain among children: a randomized controlled trial. CMAJ 2005;172:1691-5.

13. Sethna NF, Verghese ST, Hannallah RS, et al. A randomized controlled trial to evaluate S-Caine Patch ${ }^{\mathrm{TM}}$ for reducing pain associated with vascular access in children. Anesthesiology 2005;102:403-8.

14. Shainhouse T, Cunningham BB. Topical anesthetics: physiology, formulations and novel delivery systems. Am J Drug Deliv 2004;2:89-99.

15. Cohen Reis E, Holubkov R. Vapocoolant spray is equally effective as EMLA cream in reducing immunization pain in school-aged children. Pediatrics 1997; 100:E5.

16. Mawhorter S, Daugherty L, Ford A, et al. Topical vapocoolant quickly and effectively reduces vaccine-associated pain: results of a randomized, single-blinded, placebo-controlled study. J Travel Med 2004;11:267-72.

17. Maikler VE. Effects of a skin refrigerant/anesthetic and age on the pain responses of infants receiving immunizations. Res Nurs Health 1991;14:397-403.

18. Abbott K, Fowler-Kerry S. The use of a topical refrigerant anesthetic to reduce injection pain in children. J Pain Symptom Manage 1995;10:584-90.

19. Ramsook C, Kozinetz CA, Moro-Sutherland D. Efficacy of ethyl chloride as a local anesthetic for venipuncture and intravenous cannula insertion in a pediatric emergency department. Pediatr Emerg Care 2001;17:341-3.

20. Costello M, Ramundo M, Christopher NC, et al. Ethyl vinyl chloride vapocoolant spray fails to decrease pain associated with intravenous cannulation in children. Clin Pediatr (Phila) 2006;45:628-32.

21. Frequently asked questions - Gebaur's Pain Ease ${ }^{\circledR}$ [website of Gebauer Company]. Available: www.gebauer.com/Default.asp?strAction=PEFAQ (accessed 2008 May 14).

22. Grossi E, Borghi C, Cerchiari EL, et al. Analogue chromatic continuous scale (ACCS): a new method for pain assessment. Clin Exp Rheumatol 1983;1:337-40.

23. Stinson JN, Kavanagh T, Yamada J, et al. Systematic review of the psychometric properties, interpretability and feasibility of self-report pain intensity measures for use in clinical trials in children and adolescents. Pain 2006;125:143-57.

24. Duff AJA. Incorporating psychological approaches into routine paediatric venepuncture. Arch Dis Child 2003;88:931-7.

25. Cohen LL, Blount RL, Cohen RJ, et al. Children's expectations and memories of acute distress: short- and long-term efficacy of pain management interventions. $J$ Pediatr Psychol 2001;26:367-74.

26. Kelly AM. Setting the benchmark for research in the management of acute pain in emergency departments. Emerg Med (Fremantle) 2001;13:57-60.

27. Powell CV, Kelly AM, Williams A. Determining the minimum clinically significant difference in visual analog pain score for children. Ann Emerg Med 2001;37: 28-31.

28. Zempsky WT, Anand KJS, Sullivan KM, et al. Lidocaine iontophoresis for topical anesthesia before intravenous line placement in children. J Pediatr 1998;132:1061-3.

29. Selby IR, Bowles BJM. Analgesia for venous cannulation: a comparison of EMLA (5 minutes application), lignocaine, ethyl chloride and nothing. J R Soc Med 1995; 88:264-7.

30. Kleiber C, Sorenson M, Whiteside K, et al. Topical anesthetics for intravenous insertion in children: a randomized equivalency study. Pediatrics 2002;110:758-61.

31. Taddio A, Shah V, Gilbert-MacLeod C, et al. Conditioning and hyperalgesia in newborns exposed to repeated heel lances. JAMA 2002;288:857-61.

32. Krauss B, Green SM. Sedation and analgesia for procedures in children. N Engl J Med 2000;342:938-45.

33. Wu LR, Parkerson J, Doraiswamy PM. Health perception, pain and disability as correlates of anxiety and depression symptoms in primary care patients. $J A m$ Board Fam Pract 2002;15:183-90.

34. Ost LG. Blood and injection phobia: background and cognitive, physiological and behavioral variables. J Abnorm Psychol 1992;101:68-74.

Correspondence to: Dr. William M. Splinter, Department of Anesthesiology, Children's Hospital of Eastern Ontario, 401

Smyth Rd., Ottawa ON K1H 8L1; fax 613 738-4815;

splinter@cheo.on.ca 